\title{
International Discourses in Pakistani Print Media Editorials During the year 2020: A Comparative Analysis of English and Urdu Press
}

\author{
Dr. Fazli Hussain \\ Assistant Professor \\ Department of Media Science \\ ILMA University Karachi Pakistan \\ fazlihussainsheikh@gmail.com \\ $\&$ \\ Dr. Noreen Aleem \\ Assistant professor \\ Sindh Madressatul Islam University \\ Karachi - Pakistan \\ noreen.aleem@smiu.edu.pk
}

\begin{abstract}
Looking through the history it has been observed that international discourses have become a major portion in Pakistani media. This study explores the international discourses in the editorials of print media in Pakistan. Being an active part of Global village, international relations for Pakistan are game-changer-cordial for survival, sustainability, and development. In the same lines, media discourses are important to keep the citizens informed while the editorial discussions play the leading and guiding role in the process. A proper and true portrayal of international events and its linkage with the country's interests in the editorials, reflects the Agenda Building character of the Press. In Pakistan, Urdu as a national language is the linking and communicational medium among the masses and understood by 90 percent of the citizens while English is the official language, spoken by less than 2 percent of public. But besides the tabloids, there is a distinct division of National Press in English and Urdu Press whereas English Press is generally considered more objective and policy-oriented while Urdu Press is
\end{abstract}




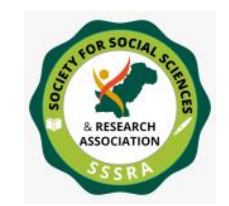

said to be the medium of commons people. Therefore, different approaches towards national and international discourses are assumed based on the general conceptions of the masses. This research investigates the editorials of daily Jang and daily Dawn, which are the most read national newspapers of Pakistan, from Jan.1, 2020, to Dec.31, 2020, to locate the comparative framing of contents concerning the international discourses. This paper also provides workable data for the political communication relevant to the editorial policies of the press in Pakistan.

Keywords: Pakistani Media, International news, editorials, print media, international discourses.

\section{Introduction}

Press as the mirror of society reflecting the collective behavior of the governing and governed entities of the state whereas the news media plays the Agenda Setting and Agenda Building role before the creation of individual and general will (Sial, 2010). By principles, press professionalism insists on impartial, unbiased, and objective discourses but in practice, all around the world, the press is subject to national interests and so its disseminations revolve around the national narratives within the prescribed parameters in the legal systems (Mirza, 2020). But still, conventional media are a powerful tool of shaping public opinion and the effective mean of constructing presumed understanding. Significantly, a reflection of national and international issues in the press acquires magnificent importance for policymaking in the domains of national and foreign affairs. Because the sorting mechanism of key issues and the editorial analysis provides expert lines for the discursive analog to follow the most opted direction in decision making. Editorials of news media interpret the policy lines of the paper on one hand and depict the most important trending issues on the other so that editorials frame the strategical directions for policymakers in a very systematic way.

Generally, editorials reproduce the ideological, political, economic, cultural, and strategic context in workable content (Pool, 2020). How the international issues are portrayed in the press and especially in the editorials is something not very simple. There is a constitutional roadmap for the dissemination of news content articulated 


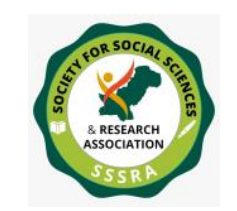

as articles 19 and 19A [Constitution of Pakistan 1973] which say, "Every citizen shall have the right to freedom of speech and expression, and there shall be freedom of the press, subject to any reasonable restrictions imposed by law in the interest of the glory of Islam or the integrity, security or defense of Pakistan or any part thereof, friendly relations with foreign States, public order, decency or morality, or about contempt of court or incitement to an offense", " Every citizen shall have the right to have access to information in all matters of public importance subject to regulation and reasonable restrictions imposed by law".

Here the friendly relation with friendly states is a meaningful intervention in the freedom to manipulate the right of expression and the way of dissemination. Mazhar Abbas (2018) unveils the implied angling and the compelling threats in article 19 in these words, "The Article 19, like many other articles of the Constitution, only guarantees freedom on 'paper' but in reality, the media remains suppressed not because of 'reasonable restrictions' but unreasonable restrictions through unlawful means". In such a framed dilemma, the editorial discourses of international issues are the reflection of state policy but at the same time, editorial choices and discussions are guided by professional fervor under the visionary guidelines of Quaid-e-Azam Muhammad Ali Jinnah which demonstrates, "I want you to keep your heads up as citizens of a free and independent sovereign State. Praise your Government when it deserves. Criticize your Government fearlessly when it deserves, but do not go on all the time attacking, indulging in destructive criticism, taking delight in running down the Ministry or the officials". (Quaid-eAzam/Qoutes, 2021). The crucial aspect of the scenario is the credibility of editorials and the professionality of its framing. In Pakistani Press, editorial policies reflect the state's interests on one hand while the publication's interests on the other but journalists are brave enough to incorporate the realities between the lines (Rasheed, 2020).

This study is focused on the discourses of international contents in the editorials of leading newspapers "daily Jang' and daily Dawn" and attempts to map up the approaches of Urdu and English press towards foreign issues. In the same sources, the paper will unravel the editorial policies of Urdu and English concerning international events framing. Also, the results will proclaim the trending international values in Print mediums in Pakistan. 


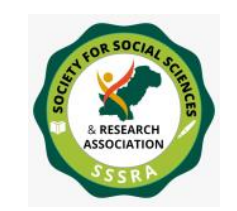

Pak. Journal of Int'L Affairs, Vol 3, Issue 2 (2020)

International Discourses in Pakistani Print...

\section{Objectives of the Study}

This study attempts to conduct a comparative analysis of the editorials of Urdu (daily Jang) and English (daily Dawn) concerning International Discourses. The main objective of the study is to disentangle the editorial policies and to explicate the framing of foreign content in the editorial discussions in the leading national dailies. The study is also aimed to explore the professional standards in editorials regarding international events in the National Press and to dismantle the critical lexical approaches of the press.

\section{Significance of the Study}

International relations for any country are pivotal to maintain peace and stability, to make development and base solid foreign relations leading to boast national interests. Pakistan is situated on the very threshold of strategic position and also it is playing a leading role in the framing of Global Politics and regional orders. This study provides an in-depth version of political communication and explicitly demarcates the editorial choices and that of dissemination designs of the National Press, regarding the international contents. The study will be highly helpful in the process of foreign policymaking and will be supporting to make up the Public Opinion and to create a sound and desirable General Will.

\section{Research Methodology}

This study follows both Qualitative and Quantitate domains of research to empirically explore the content (International Discourses) in the editorials of Pakistani National Press. The Quantitative Comparative study is based on the number of editorials discussing the international discourses and so that is the simple statistical operation based on the Quantitative Comparative Analysis method while for further scientific estimation, the study incorporates the Critical Discourse Analysis (CDA) which comes under the sphere of Qualitative research module.

The Quantitative Comparative Analysis (QCA) is the most fitted paradigm for the study of comparative approaches in social sciences and also it is the goal-driven mechanism in the case of this study (Mahney, 2012). Similarly, Teun A. van Dijik suggests the CDA for the study of discourse exploration related to text, language, 


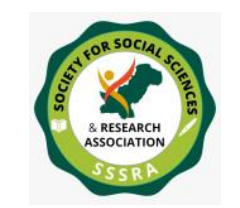

Pak. Journal of Int'L Affairs, Vol 3, Issue 2 (2020)

International Discourses in Pakistani Print...

and semiotics (Dijik, 2000) which this study is incorporating in its analysis to effectively identify the editorial discussions concerning international discourses in the National Press of Pakistan.

\section{Research Questions}

This study attempts to answer the questions about the framing of International Discourses in print media in Pakistan. The questions are based on the assumption that there is a vivid difference in the editorial policies of Urdu and English press in the country.

Q1. English Press covers more international content than that of the Urdu Press

Q2. English Press is more Objective and impartial than the Urdu Press

\section{Research Sample}

This research analyzes the editorials published by two leading National Newspapers (daily Jang and daily Dawn) from January 1, 2020, to December 13, 2020, concerning the framing of international content. The study is focused on the quantitative comparative analysis (QCA) as well as centered on Critical Discourse Analysis (CDA). In this way, the research will be able to critically answer the research questions given above.

\section{The course of the study, newspapers, and editorials}

The research is based on the analysis of editorials of two leading newspapers of the National Press System of Pakistan. Daily Jang is the most read newspaper in the Urdu Section of Press while daily Dawn is representing the English Press in the same category. The study explores editorials published from January 1, 2020, to December 31, 2020, with zero skips because the selective sample could create some doubts in the missing parameters. The total editorials published by daily Jang in the year 2020 were found $360 \times 3=1071$ while in the same timepiece daily Dawn published $360 \times 3=1071$ too. A total of 2142 editorial were investigated and analyzed for the content "International Discourses" [Table1 ]. Furthermore, a total of 525 editorial were published having International Discourses. The editorials published with International Discourses in daily Jang were found 294 while on the same subject, daily Dawn published 231 editorials [Table 2]. 


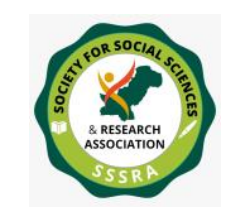

\section{Analysis and Discussion}

The statistics of editorial reveal that the national press publishes an accountable number of editorials concerning international discourses. During the year 2020 (Jan 1, to Dec 31) daily Jang published 1071 editorials out of which 294 (27\%) were included in the international content, similarly, daily Dawn published 1071 editorials out of which $231(22 \%)$ were regarding the international discourses.

It's very important to note that the data results, prove the general perception about the English (foreign oriented), false. The statistics illustrate that Urdu Press publishes more international content than the English Press in Pakistan. The data also negates the general conception about the National Press that Urdu Press is focused on local content while the English press is mostly inclined to foreign content.

Similarly, the major events on the international stage are accountably addressed in the national press with zero negligence. It's proved that the national press not only accommodates the local political, social, economic, and other small narratives but also it professionally, disseminates the internal discourses.

In this sense, the national press plays an active role in educating the public and keep them in touch with the events and developments on national and international levels. Moreover, the Urdu Press gives more head to the internal discourses and tries to involve the readers in international politics, social and economic developments at large due to its larger readership. At the same time, English papers are mostly read by the elite class and policymakers, so its dissemination on international content provides in-depth information and investigative information about the external frame of relations.

The statistical data Table 3 reveals that both the Urdu and English Press cover and frame international discourses under the same policies and negates the perception that English Press gives more weightage to international contents than the Urdu Press.

Thereafter, the analysis shows some interesting facts regarding the coverage priorities of the Urdu and English press. Urdu Press covers mostly the content 


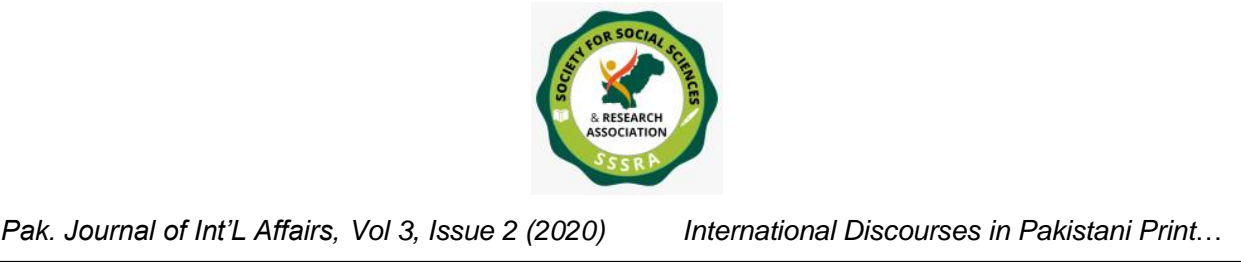

related to Afghanistan USA and India more than the English Press whereas the English press covers more counties of the world than that the Urdu Press covers.

\section{Discourse analysis}

Nonetheless, the press in general is expected and also it pretends to be impartial but everywhere in the world each media system has to operate within the parameters laid down by the constitution of the state and in the limits of the state's interests where Pakistani media system is no exception, so the editorial policies are naturally subject to the foreign policies of the state governed by national interests. The popular narratives, the friendly media coverage, and politicization of content are common in the discourses of the press all around the world.

Most of the editorials published by the national press revolve around the neighboring countries, Afghanistan, India, China, and Iran but also a major part of the content is focused on the USA, Saudi Arabia, and Turkey but amazingly during the year under study (2020), no touch was seen about France, Malaysia, Britain, Russia and other major players of the Power Game in the region.

According to Dijik, (2006), the discourse analysis properly deals with the explicates of common sense in the ideologies so for the detailed account of the international contents in the editorials of National Press in Pakistan, the study employs the Critical Discourse Analysis (CDA) mechanism to locate the trending values in the disseminations of foreign content in Urdu and English press. For the explicit, investigation, the study explores and analyzes the discourse under comparative mechanics of research as Lie Y. (W, 2016) predicts that newspapers are possibly the appropriate sources consuming more space to discourse and scrutinize substantial issues of national and international implication rather than done by other news mediums ( $\mathrm{Pu}, 2006)$.

\section{Major International discourses and comparative CDA of editorials (Dawn, Jang)}

Mostly the year 2020 remained structured in the claws of Covid-19 and its impacts on the political, economic social, and strategic domains but the business of war also painted its strains alongside. An accountable lack of cooperation among the states 


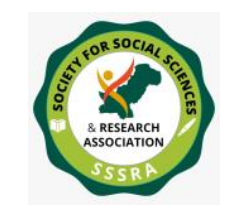

Pak. Journal of Int'L Affairs, Vol 3, Issue 2 (2020)

International Discourses in Pakistani Print...

and the international instrument was witnessed as the bad fat of the world all around. The aggressive moods in international politics and trading were recorded and also partiality, double standards, and clinging to fake national interests were noted during the year 2020. In such a scenario, the discourses of major international events in editorials are very important to be explored for the purpose to located the trending of publishing policies of the country's press.

At the same time, the lexical approaches and the use of functional words determine the trending values of texts (Rechardson, 2007) so that the paper attempts to analyze the editorials published by daily Dawn and daily Jang in this context. Similarly, it's the impetus to look into the framing of the international discourses through universal lenses because generally, newspapers filter the international contents through the nationalistic lenses while framing their editorial or devising their publishing policies (yin, 2007).

US kills Qassem Soleimani. On January 3, 2020, the US killed the Iranian General Qassem Soleimani in an airstrike in Iraq (BBC, 2020), the news spread around the world like wildfire escalating tension in the already deteriorating relations between the USA and Iran. The event was responded in all mediums of communication around the world and different comments and reactions were recorded. Pakistani Media also gave head to the content and several editorials were published covering the proceedings of attack and the following outbreaks with a specific glance.

On January 4, daily Dawn published an editorial under the leading "Soleimani's Killing" (Dawn d. , 2020). The lexical approach was very supportive of Iran and the US strike was condemned in functional words like, 'Reckless', 'foolish', and 'provocative'. The editorial termed the killing of Soleimani as "the spark that sets the Middle East alight in a new conflagration”.

Similarly, a day later (Jan 5), daily Jang also published an editorial covering the killing of Gen Soleimani, bearing the lead "Dunya Barood $k$ dher par" the world on the heap of explosives, (Jang, 2020). The language of the editorial reflects the anger of the Muslims against America and Israel for example "America Jang Par Tula Hua hey" (America is intended to wage a war). The course continued and on the $6^{\text {th }}$, $7^{\text {th }}, 8^{\text {th }}, 10^{\text {th }}, 11^{\text {th, }}$ and $13^{\text {th }}$ of January, daily Jang published editorials following the USA-Iran relations with a highly critical tone for the moves from Donald Trump. 


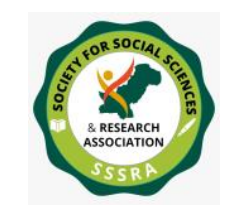

Pak. Journal of Int'L Affairs, Vol 3, Issue 2 (2020)

International Discourses in Pakistani Print...

The paper also suggested Pakistan meditate for peace and not to be part of the US war as that has brought negative consequences always for the Nation.

The language used in the editorials regarding the US attacks and the aftermath is critical, like on the $9^{\text {th }}$ January's editorial Dawn wrote the US's denial of Visa to Iranian FM in these words, "If America's adversaries are not allowed to come to New York for UN sessions, then the democratic spirit of the body is violated". The National Press of Pakistan follows the popular narrative for its editorials. Also, the lexical approach reflects that Print media represent the tone of its readers effectively.

Although, some other major international events were recorded like the Air Strike on Tripoli on the $4^{\text {th }}$ of January (MAGDY, 2020), the violence in Beirut (ROSA, 2020), Erdoğan's moves regarding France, Greece, and the Gen Haftar (BECATOROS, 2020), the Ukrainian plane crash in Iran ( (Dawn, 2020) and UN Security Council's embargo on Central Africa (RATER, 2020). But no editorial was published either by daily Dawn or by daily Jang on these international discourses.

The Indian content. After the partition of British India in 1947, Pakistan and India came into being as two independent states but several issues remained unsolved including the princely state of Kashmir. The issues injected a sense of hatred which led to conflicts and wars between the two neighboring countries. In this regard, the history of the region witnessed three open wars in 1948, 1965, and 1971. The content of hate, due to the unresolved issues between India and Pakistan, is reflected in the state policies and the social behavior of the masses and also in the institutional policies including the print media's publishing manners.

The Critical Discourse Analysis of the editorials published by leading newspapers of Pakistan (daily Jang and daily Dawn) indicates that both the English and Urdu Medium of mass communication follows the popular narratives regarding the Indian Content in their editorials.

On January 31, 2020, daily Dawn published an editorial under the title "Indian bellicosity", which very implicitly demarcates the policy of the paper and the tone of the popular narration of masses in Pakistan. The editorial embodies the country's 


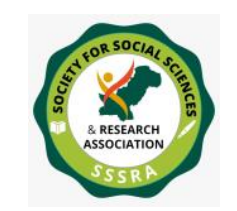

Pak. Journal of Int'L Affairs, Vol 3, Issue 2 (2020)

International Discourses in Pakistani Print...

policy towards India and also it speaks the ideology of the state concerning India as a permanent enemy. The word "bellicosity" means "a natural disposition to fight" which reflects the common sense created in the mind of masses in the country. It's important to note that the underlying ideologies in the text of editorial discourses have a profound impact on the process of Agenda Setting. In this regard, the CDA asserts to analyze based on positive self and negative others as Richardson (2007, p. 47) says "words convey the imprint of society and value judgment in particular-they convey the connoted as well as denoted meanings".

Similarly on the same day (Jan.31, 2020), daily Jang published its editorial "trans: Intimidation of Modi". The tone of the editorial is the same as used by daily Dawn. Jang writes "the statement by Indian Prime Minister Narendra Modi denotes his wary nature". Both the Urdu and English press in Pakistan follows the same policy regarding Indian Content.

In the same vein, on February 25, 2020, daily Dawn published its editorial "Trump in India". The lexical analysis determines that the paper is highly partisan in the selection of words while discussing the visit of the US president to India. Proving the similarity between Trump and Modi, the editorial says "Both are political outsiders who have managed to reach the top of their respective systems through a blend of right-wing populism and maverick ideas". The words outsiders and maverick ideas indicate the popular narrative in Pakistan about the India-US relation. More in this respect, the paper published another editorial on February 29, 2020, under the title "Indo-US arm deal" and described it in the words as "ONE of the more troubling outcomes of US President Donald Trump's just-concluded visit to India is a multibillion-dollar arms deal reached between Washington and New Delhi". Here the word "Troubling outcome" indicates the sentimental meaning directing the public opinion-making in accordance with state policy.

Following the same context on February 26, 2020, daily Jang discussed Trump's statement in these words "trans: the USA is the biggest guardian and "Murabi" of India in South Asia". The CDA analysis indicates that the editorial of daily Jang explicitly represents the state policy and the public opinion. In the same editorial, Jang implies Trump's visit to India as a precursor to confine China by supporting and strengthening India. Daily Jang published 6 editorials from February 26 to 29, 2020 in the same context. 


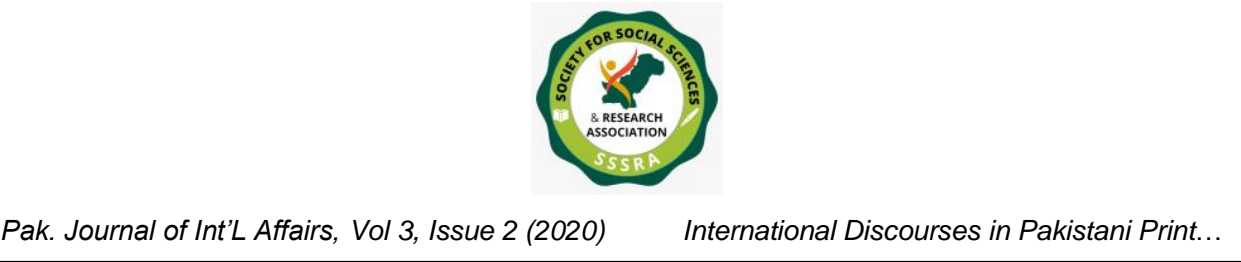

Conclusively, the press in Pakistan is highly polarized regarding the Indian Content in its discourses. Here the assumption that English Press in Pakistan is impartial and objective in Framing the news content and its unbiased regarding its editorial policy, is negated. It's proved that both the Urdu and English media are on one page while framing the Indian and US content.

Also, it's proved that the international discourses are selective and are in accordance with national interests. Most of the editorials are covering India, the USA, Afghanistan, China, and Iran. In some cases, Canada, France, Britain, and Turkey are covered but there is coverage where the country's policy is not concern or clear.

\section{Conclusion}

The study explored the Urdu and English Press of Pakistan under the Quantitative Comparative Analysis (QCA) and Critical Discourse Analysis (CDA) mechanism of research and found that both the English and Urdu Press cover most of the international discourses in their editorials. It's empirically proved that during the year 2020 (Jan 1, to Dec 31) daily Jang published 27\% of its editorials covering international content, similarly, daily Dawn published $22 \%$ editorials discussing international discourses. The statistics negate the assumption that English Press covers more international content than that of the Urdu Press and so question One is dissatisfied.

In the same manner, the CDA proves that both the English and Urdu Press lexical approach is on the same path, representing the popular narrative of the state. The language and the usage of terms denote the positive-self and negative-other, especially in the case of India and the USA. The editorials by both the English and Urdu Press show a soft corner for China and Iran, while present a balanced approach for the other international issues like Yemen, Syria, the Kingdom of Saudi Arabia, Iraq, and Germany. Subsequently, the analysis disapproves the assumption that English Press is more Objective and Impartial than the Urdu Press. In this way, the second research question is also dissatisfied. 


\section{References}

Abas, M. (2018, May 3). Article 19 and threat to media. The News International. https://www.thenews.com.pk/print/311886-article-19-and-threat-to-media.

BBC. (2020, January 3). Qasem Soleimani: US Kills Top Iranian General In Baghdad Air Strike. Baghdad, Iraq. https://www.bbc.com/news/worldmiddle-east-50979463.

Becatoros, E. (2020, January 17). Libya's Rival Military Commander Seeks Support In Greece. APNews. https://apnews.com/article/70434dca3901c115a74d4a8d369f6e12

Dawn. (2020, January 8). Ukrainian Airline Crashes After Take-Off In Iran, Killing All 176 Aboard. https://www.dawn.com/news/1527012.

Dawn. (2020, January 4). Soleimani's Killing. https://www.dawn.com/news/1526186/soleimanis-killing

Dijik, T. A. (2000). New (s) Racism: A Discourse Analytic Approach, in Ethnic Minorities And The Media: Chang Ing Cultural Boundaries. Buckingham: Open University Press.

Hook, S. W., \& Pu, X. (2006). Framing Sino-American Relations under Stress: A Reexamination of News Coverage of the 2001 spy plane crisis. Asian Affairs: An American Review, 33(3), 167-183.

Magdy, S. (2020, January 5). Libyan authorities report airstrike on military academy. APNews https://apnews.com/article/e743d7fa9b6bbad7c4226a48de4a1dd7

Mahney, G. G. (2012). A Tale of Two Cultures: Qualitative and Quantitative Research in Social Sciences . Princeton New Jersey USA: Princeotn University Press.

Mirza, M. (2020, November 20). Press in Pakistan, Objectivity and Professionalism. (D. F. Hussain, Interviewer). 
Pool, E. (2020). Reporting Islam: Media Representations of British Muslims. Bloomsbury: Bloomsbury Academic.

Quaid-e-Azam Mohammad Ali Jinnah. (2021, January 28). Quotes from the Quaide-Azam Mohammad Ali Jinnah. Nazariat Pakistan Trust. http://nazariapak.info/Quaid-e-Azam/Qoutes.php.

Rasheed, H. (2020, 11 25). Press freedom in Pakistan. (D. F. Hussain, Interviewer)

Rater, P. (2020, Febuary 1). Russia Obtains Ease On C.Africa Arms Embargo At UN Security Council. Yahoo News. https://news.yahoo.com/russia-obtainsease-c-africa-arms-embargo-un-221056411.html

Rechardson, J. (2007). Analyzing newspapers: An Approach Form Critical Discourse Analysis. New York: Palgrave MacMillan.

Rosa, S. E. (2020, January 20). Violence escalates in Beirut as protesters clash with Police. AP News. https://apnews.com/article/c4fe889e9588c83604a8f8defba6c7c0

Mezzera, M., \& Sial, S. (2010). Media and Governance in Pakistan: A Controversial Yet Essential Relationship. Initiative for Peace Building. https://www.clingendael.org/sites/default/files/pdfs/20101109_CRU_public atie_mmezzera.pdf.

Lei, Y. W. (2016). Freeing the press: How field environment explains critical news reporting in China. American Journal of Sociology, 122(1), 1-48.

Yin, J. (2007). The clash of rights: A critical analysis of news discourse on human rights in the United States and China. Critical Discourse Studies, 4(1), 7594. 
Tables

Table 1

Editorials published by daily Jang and daily Dawn from Jan 1, 2020 to Dec 31, 2020

\begin{tabular}{lllll}
\hline \multicolumn{1}{c}{ Months } & Daily Jang & Daily Dawn & Frequencies & $\begin{array}{l}\text { Cumulative } \\
\text { Freq }\end{array}$ \\
\hline Jan & 93 & 93 & 186 & 186 \\
Feb & 87 & 87 & 174 & 360 \\
Mar & 93 & 93 & 186 & 546 \\
Apr & 90 & 90 & 180 & 726 \\
May & 84 & 84 & 168 & 894 \\
Jun & 84 & 84 & 168 & 1062 \\
Jul & 93 & 93 & 186 & 1248 \\
Aug & 84 & 84 & 168 & 1416 \\
Sep & 90 & 90 & 180 & 1596 \\
Oct & 90 & 90 & 180 & 1776 \\
Nov & 90 & 90 & 180 & 1956 \\
Dec & 93 & 93 & 186 & 2142 \\
Total & 1071 & 1071 & 2142 & \\
\hline
\end{tabular}

Note: The table indicates that both daily Jang and daily Dawn published 1071 editorials during the year 2020-2021. The range is minimum 84 and maximum 93.

Table 2

Frequencies of the editorials in Pakistani Press with International Discourses

\begin{tabular}{lllll}
\hline Months & Daily Jang & $\begin{array}{l}\text { Daily } \\
\text { Dawn }\end{array}$ & Frequencies & $\begin{array}{l}\text { Cumulative } \\
\text { Freq }\end{array}$ \\
\hline Jan & 27 & 30 & 57 & 57 \\
Feb & 30 & 17 & 47 & 104 \\
Mar & 26 & 22 & 48 & 152 \\
Apr & 23 & 25 & 48 & 200 \\
May & 27 & 19 & 46 & 246 \\
\hline
\end{tabular}




\begin{tabular}{lllll}
\hline Jun & 19 & 12 & 31 & 277 \\
Jul & 21 & 21 & 42 & 319 \\
Aug & 19 & 15 & 34 & 353 \\
Sep & 24 & 14 & 38 & 391 \\
Oct & 22 & 14 & 36 & 427 \\
Nov & 29 & 19 & 48 & 475 \\
Dec & 27 & 23 & 50 & 525 \\
Total & 294 & 231 & 525 & \\
\hline
\end{tabular}

Note: The table demonstrates that daily Jang publishes more editorial with reference to international content (294) as compared to the editorials published by daily Dawn (231) in the same span of time Jan 2020-Dec 2020).

\section{Table 3}

Frequency of editorials published by daily Jang and daily Dawn from Jan 1, 2020 to April 30, 2020, with reference different countries

\begin{tabular}{lllll}
\hline Countries & Daily Jang & Daily Dawn & Frequencies & $\begin{array}{l}\text { Cumulative } \\
\text { Frequencies }\end{array}$ \\
\hline USA & & & & 33 \\
INDIA & 18 & 15 & 33 & 69 \\
IRAN & 19 & 17 & 36 & 78 \\
AFGHANISTAN & 20 & 5 & 9 & 105 \\
CHINA & 3 & 7 & 27 & 111 \\
TURKEY & 1 & 3 & 6 & 113 \\
KSA & 1 & 1 & 2 & 117 \\
UK & 1 & 2 & 3 & 120 \\
SYRIA & 0 & 2 & 3 & 121 \\
GERMANY & 0 & 1 & 1 & 122 \\
UAE & 0 & 1 & 1 & 123 \\
BANGLADESH & 0 & 1 & 1 & 124 \\
MYANMAR & 0 & 1 & 1 & 128 \\
IRAQ & 1 & 2 & 2 & 129 \\
SARI LANKA & 0 & 1 & 2 & 131 \\
YEMEN & 0 & 1 & 1 & 132 \\
RUSSIA & 1 & 3 & 3 & 133 \\
QATAR & 1 & 0 & 1 & \\
\hline & & 0 & 1 &
\end{tabular}




\begin{tabular}{lllll}
\hline GENERAL & 36 & 31 & 67 & 200 \\
G. TOTAL & 106 & 94 & 200 & \\
\hline
\end{tabular}

Note: The table shows that daily Jang published 106 editorials from January 1 to April 30. Most (35.8\%) of the editorials were on general topics with reference to international contents followed by Afghanistan (18.8), India (17.9\%), USA (16.9\%), Iran (3.8\%), China (2.8\%), Turkey, KAS, UK, Iraq, Russia and Qatar .9\% each.

Similarly, the table indicates that daily Dawn published 94 editorials discussing the international content. Most (33.4\%) of the editorials were covering the general topic while $18 \%$ were on India following by USA by $15.9 \%$, Afghanistan by $7.4 \%$, Iran by $5.3 \%$, China by $3.1 \%$, Yemen by $3.1 \%$ KSA, UK and Myanmar by $2.1 \%$ each and Turkey, Syria, Germany, UAE, Bangladesh, Iraq and Sri Lanka by $1.06 \%$ each. 